ORIGINAL ARTICLE

\title{
Investigation of Social Appearance Anxiety in University Students
}

\author{
SEMRA ÇETIN, ${ }^{*}$ CUMA ECE* \\ * Sakarya University of Applied Sciences Physical Education and Sport faculty, Sakarya/ TÜRKIYE
}

\begin{abstract}
The aim of this study is to investigate Social Appearance Anxiety in university students according to gender, type of faculty, grade level, body weight and height. The present study was conducted on students of Sakarya University who were between the ages of 17 and 25. 247 of the participants were female and 256 were male. The social appearance anxiety scale filled in by 503 students was evaluated. T-test, one-way analysis of variance and LSD tests were used in statistical operations. In this study, the Social appearance anxiety scale score was found to be slightly lower in women than in men in the comparison made by gender. This difference did not show a statistically significant difference according to gender $(p>0.05)$. The social appearance anxiety score differs statistically significantly according to the type of education and training faculties $(p<0.001)$. Social appearance anxiety changes significantly according to education level $(p<0.001)$. It was found that the students who were satisfied with their body weight and height had lower social appearance anxiety than the students who were not satisfied. Social appearance anxiety varies according to height and body weight category $(p<0.001)$.

In conclusion, social appearance anxiety was found to be similar according to gender in this study. It differed according to the field of study of the students. The social appearance anxiety levels of the students receiving sports education are the lowest. Anxiety levels of students who receive art education are higher than those who receive sports education. The social appearance anxiety of the students who did not receive sports and art education is the highest. In order to reduce social appearance anxiety, students should be supported in sports and art education and practice.
\end{abstract}

Keywords: University student, Social Appearance Anxiety, Sports, Education, Age and Height

\section{INTRODUCTION}

People experience anxiety when they think they cannot make a positive impression on others (Leary \& Kowalski, 1995). This resulting anxiety is called social appearance anxiety. Social appearance anxiety occurs when people's physical appearance is evaluated by other people. In other words, it is the emotional state that people feel towards the evaluation of their physical image by others (Çınar and Keskin, 2015). Social appearance anxiety has negative effects on the social, academic and professional aspects of individuals (Dindar and Akbulut, 2015). Social appearance anxiety is about the appearance of an individual. Social appearance anxiety includes an individual's thoughts about his/her body rather than his/her physical appearance (Yüceant and Unlü,2017). Social appearance anxiety is what individuals feel about the assessment of their physical build by others. Individuals have their own perceptions about their physical build. Some individuals feel anxious about how their appearance is perceived by others (Mülazımoğlu Ballı et al., 2014). The concept of social appearance anxiety is a more comprehensive concept that includes an individual's skin colour and face shape beyond the individual's general physical appearance such as height, weight and muscle build (Hart et al., 2008). Social appearance anxiety is a broader concept that includes features such as skin color, face shape, blushing and embarrassment, beyond general appearance such as height, weight and muscle structure (Kara, 2016). In other words, it includes a more detailed and holistic structure beyond the general physical appearance (Hart et al., 2008). It is stated that social appearance anxiety is positively related to social anxiety and negative body image. It is also stated to be positively associated with emotional problems (eg, depression, anxiety) and interpersonal problems (suspicious, submissive),(Claes et al., 2012).
People develop feelings, attitudes and behaviors about their bodies according to the ideal measures determined in the society. Not having these socially accepted measures can cause negativities in terms of selfevaluation in people (Yamak et al., 2016). There is a relationship between physical self-respect, body satisfaction, diet, motivation to physical activities, and physical activities and social appearance anxiety (Yousefi et al., 2009). People who evaluate themselves physically well are more secure in their relationships and more successful in their profession. On the other hand, those who think that they have many bad sides feel restless, insecure and worthless. It is expected that university students who are not satisfied with their physical structure will experience some psychological problems (Kılıç, 2015). Physical activity elicits a sense of personal identity, social identity and group membership in people. Participating in physical activity increases self-understanding and selfconfidence in individuals. It develops social communication skills, cooperation increases. It helps to reduce mental fatigue and tension (Gür and Küçükoğlu, 1992).

In this study, it is aimed to: Does social appearance anxiety vary by gender?

Has social appearance anxiety changed according to the type of faculty studied? In addition, does social appearance anxiety differ according to the variables of years of education? It was also investigated whether social appearance anxiety differs according to the variables of doing sports, body weight and height satisfaction.

\section{METHOD}

This research is a general screening model study conducted to test whether university students have social appearance anxiety levels. General screening models target a specific population of a study, or a group or sample from that target population, and are used to make a general 
judgment about that population, which can consist of many elements.

Participants: The present study was conducted on students of Sakarya University who were between the ages of 17 and 25. 247 of the participants were female and 256 were male. Appropriate sampling method was used in the selection of individuals to participate in the study group. The students were studying in the Faculty of Sport Sciences, the Faculty of Fine Arts and the Social Sciences departments of the Faculty of Education. A questionnaire form including personal information and social appearance anxiety scale was given to students. Of these forms, the forms of 503 students who filled in the questionnaire and the scale in full were assessed.

Appearance Anxiety Scale: The Social Appearance Anxiety Scale was developed by Hart et al., (2008) to identify fear situations in which the general appearance of the person, including but not limited to body shape, can be evaluated. As a result of the reliability studies of the scale, which was adapted into Turkish by Doğan (2010). The test-retest reliability coefficient was calculated as .85. This scale consists of 16 questions. It is a 5-Likert type scale. It is the items are answered as (1) Not at all characteristic of me, (5) extremely characteristic of me.

Statistical Processes: SPSS 25.00 package program was used for statistical processes. The data obtained from the scale were calculated in accordance with the scoring directive. While evaluating the data, its suitability to normal distribution was investigated with the "Kolmogorov Smirnov Test" and it was found that all data were distributed normally. T-test, one-way analysis of variance and LSD tests were used in statistical operations.

\section{RESULTS}

Tables regarding the anthropometric characteristics and social appearance concerns of the participants included in the study are given below.

Significant differences were found in weight, height and body mass index values of both genders $(p<0,001)$. Social appearance anxiety scale score was found as 33.90 in women and as 34.57 in man. In this study, no statistically significant difference was found in social anxiety scale scores according to gender ( $p>0.05)$.

Table -1. Participants' anthropometric parameter and social appearance anxiety states

\begin{tabular}{|c|c|c|c|c|c|}
\hline & & $\mathrm{N}$ & Average & St. deviation & $t$ \\
\hline \multirow[t]{2}{*}{ Age (Years) } & Male & 256 & 22.47 & 1.81 & \multirow[t]{2}{*}{1.26} \\
\hline & Female & 247 & 22.23 & 2.20 & \\
\hline \multirow[t]{2}{*}{ Height $(\mathrm{cm})$} & Male & 256 & 177.92 & 7.72 & \multirow[t]{2}{*}{$5.75^{\star *}$} \\
\hline & Female & 247 & 167.88 & 7.09 & \\
\hline \multirow{2}{*}{$\begin{array}{l}\text { Weight } \\
(\mathrm{kg})\end{array}$} & Male & 256 & 75.90 & 14.20 & \multirow[t]{2}{*}{$-13.55^{\star \star}$} \\
\hline & Female & 247 & 63.01 & 14.16 & \\
\hline \multirow{2}{*}{$\begin{array}{l}\text { Body Mass Index } \\
\left(\mathrm{kg} / \mathrm{m}^{2}\right)\end{array}$} & Male & 256 & 24.69 & 2.51 & \multirow[t]{2}{*}{$-9.15^{\star *}$} \\
\hline & Female & 247 & 23.12 & 2.42 & \\
\hline \multirow[t]{2}{*}{ Social appearance anxiety scale score } & Male & 256 & 34.57 & 9.50 & \multirow[t]{2}{*}{0.92} \\
\hline & Female & 247 & 33.90 & 9.51 & \\
\hline
\end{tabular}

${ }^{\star *} \mathrm{p}<0.001$

Table-2. Comparison of the social appearance anxiety scale scores of the students according to the type of faculty they are studying

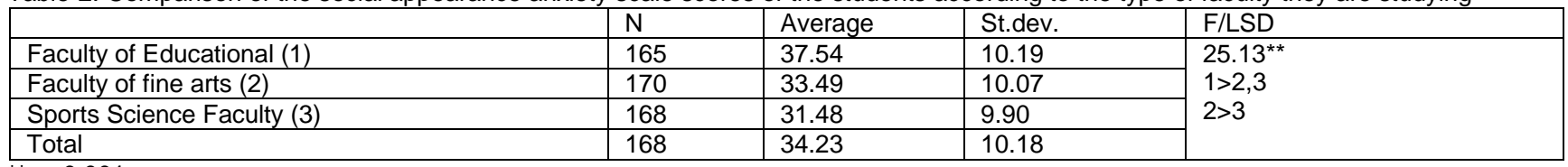

${ }_{* *}^{*} \mathrm{p}<0,001$

Social appearance anxiety score was not statistically different in this study according to the type of faculty studied ( $p<0.001)$.

Table -3. Comparison of the Social Appearance Anxiety Scale scores of the students according to the academic year

\begin{tabular}{|l|l|l|l|l|}
\hline & $\mathrm{N}$ & Average & St. deviation & $17.10^{* *}$ \\
\hline 1st year & 136 & 43.53 & 10.20 & $1>2,3,4$ \\
\hline 2nd year & 126 & 35.52 & 10.02 & \\
\hline 3rd year & 123 & 35.51 & 9.40 & \\
\hline 4th year & 118 & 32.84 & 9.04 & \\
\hline
\end{tabular}

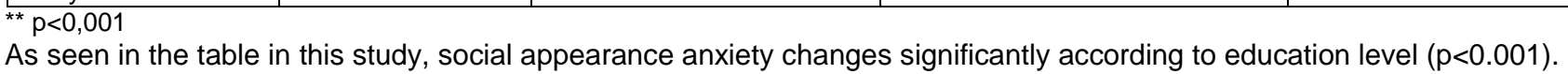

Table-4. Comparison of social appearance anxiety scale scores in terms of present weight and height states

\begin{tabular}{|l|l|l|l|l|l|}
\hline \multirow{4}{*}{ Weight } & N & $\mathrm{N}$ & Average & St. deviation & F/LSD \\
& Pleased (1) & 184 & 32.44 & 9.02 & $15.10^{\star *}$ \\
\cline { 2 - 5 } & Indecisive (2) & 104 & 34.67 & 9.02 & $1<3$ \\
\cline { 2 - 5 } & Not pleased (3) & 215 & 36.90 & 9.11 & $12.13^{* *}$ \\
\hline \multirow{3}{*}{ Height } & Pleased (1) & 184 & 32.92 & 8.81 & $1<2,3$ \\
\cline { 2 - 5 } & Indecisive (2) & 104 & 37.85 & 8.70 & \\
\cline { 2 - 5 } & Not pleased (3) & 215 & 36.44 & 8.05 & \\
\hline
\end{tabular}


In this study, a statistically significant difference was found in social appearance anxiety in categorizing according to body weight and height $(p<0.001)$.

\section{DISCUSSION}

It is seen that the average age of the students participating in this study is 22.47 for boys and 22.23 for girls. The mean body mass index was found to be $24.69 \mathrm{~kg} / \mathrm{m}^{2}$ for male students and $23.12 \mathrm{~kg} / \mathrm{m} 2$ for female students. In this study, significant differences were found in weight, height and body mass index values according to gender $(p<0.001)$. The social appearance anxiety scale score was 34.57 for men and 33.90 for women. There was no statistical difference in the social anxiety scale scores of the students according to gender $(p>0.05)$. Ideal values of body mass index are specified as 22 for men and 21 for women. However, it is suggested that higher values of +1 should be accepted for athletes (Çınar et al., 2004). Students can be accepted in the specified criteria for health.

In a study conducted by midwife (2019), it was determined that there was no significant difference in the social appearance anxiety levels of women and man students. However, it was stated that the social appearance anxiety levels of man students were higher than that of women students. Alemdağ and Öncü (2015) found statistically significant difference between social appearance anxiety scores and gender. In their study, Soylu et al.,(2017) found statistically significant difference between groups in terms of the variable of gender in social appearance anxiety scales of adolescent participants $(p<0.05)$. Man students were found to have higher social appearance anxiety when compared with women students. In a study by Çepikkurt and Çoşkun (2010), it was concluded that women were less pleased with their physical appearance and thus they had more negative feelings about their physical appearance when compared with men. Doğan (2009) found that men had higher social anxiety than women. Eren Gümüş (2006) in a study, reported that social anxiety did not differ in terms of gender. Ermiş and İmamoğlu (2019) stated in their study that social appearance anxiety in university students did not change according to gender. İmamoğlu et al. (2018) did not find a significant difference between social appearance anxieties of university students in terms of gender. In this study, no statistically significant difference was found in social anxiety scale scores according to gender (Table-1). The reasons for this are that the students participating in the research receive similar education, have similar social activities and social environment.

In a study, found that prospective teachers of physical education and sport had lower social appearance anxiety when compared with students of other departments (Alemdağ and Öncü, 2015). Tekeli (2017) found that social appearance anxiety of physical education and sport department students were higher when compared with students in other education departments. Yıldırım et al. (2011), no significant differences were found in social anxiety levels of prospective teachers studying in different departments. Tekeli (2017) found that physical education and sport department students had statistically significantly higher social appearance anxiety when compared with educational sciences students. In a study they conducted, İmamoğlu et al. (2018) found that students of sport sciences faculty had the lowest social anxiety scores, while students of fine arts faculty had higher social anxiety scores and the students of education faculty had the highest social anxiety scores. In a study, students' social appearance anxiety as the level of shyness increases, the level of shyness also increases, or as the level of shyness increases, social appearance anxiety increases (Kara, 2016). In a study conducted by midwife (2019), it was determined that there is a significant difference in the social appearance anxiety levels of students who do and do not do sports. It was determined that the social appearance anxiety levels of the students who stated that they did sports were lower than the students who stated that they did not do sports. In this study, a statistically significant difference was found between the scores of the social appearance anxiety scale according to the field of education and training. The lowest social appearance anxiety scale scores were found in students receiving sport education, while social appearance anxiety scale scores were higher in students receiving art and music education and the highest in students of educational sciences field. The reason why students receiving sport education had lower social anxiety levels when compared with other students can be the fact that they go to different places and take part in different social environments at different times for competitions they participate in and communicate with athletes and people from different cultures and they experience the feeling of self-confidence that sport gives to people (İmamoğlu et al., 2018). Art can also have similar effects. According to Heise (2004), "the intersection of art education with visual culture can create learning experiences preparing students to take part in a democratic society". Participation in exercise has been found to have positive influence on social physical anxiety (Edwards et al., 2005i; Marquez and McAuley, 2001). It was found that prospective teachers of physical education had low averages of social anxiety level (Yüceant and Unlü, 2017). In one study, found that the participants had a less than moderate level of social appearance anxiety with an average score of 32.98 (Tekeli, 2017). In the related literature, it is stated that pre-service teachers studying in different departments have less than moderate social appearance anxiety (Alemdağ and Ölçü, 2015). Sportive activities have positive influence on posture (Yamak et al., 2018) and this can have an influence on social appearance anxiety. In the present study, it can be said that students receiving sport education have less than moderate level of social appearance anxiety. In this study, social appearance anxiety varies according to faculties. Sports faculty students have the lowest anxiety. This may be caused by sports and their physical appearance being more beautiful or muscular.

In their study, Witchen and Fehm (2003) found that students in the first years of their education had higher levels of social anxiety compared to students with more advanced education. Yıldırım et al. (2011) found that students' social anxiety scale scores in the first grade were significantly higher than those in the fourth grade. Telli and 
Ünal (2016), on the other hand, determined in another study that students' social appearance anxiety differs according to age, department and education year. In their study, Alemdağ and Öncü (2015) found that the mean social appearance anxiety scores of first and second year physical education teachers were higher than those of third and fourth grade students. According to Imamoglu et al. (2018), in a study they conducted, determined that there was a significant difference between students' social appearance anxiety according to their years of education. In a study, it was found the highest level of social appearance anxiety in physical education students in their first year (Tekeli, 2017). In this study, a statistically significant difference was determined according to the classes in which the students were educated. It has been determined that first and second year students have higher social appearance anxiety than students in other classes (third and fourth grade). It has been observed that especially first grade students have high social appearance anxiety. In other words, we can say that as the years of education increase, social appearance anxiety decreases. Among the reasons for this, students' difficulties in adapting to their environment in their first years can be considered as the leading cause.

Tekeli (2017) found that the highest social appearance anxiety was found in underweight participants studying in physical education departments, and the highest social appearance anxiety was in low-weight participants studying in education faculties. In their study, Ermiş and İmamoğlu (2019) found that the social appearance anxiety injuries of students who were satisfied with their weight and height were found to be statistically significant compared to those who were not satisfied. According to Koca et al. (2018) found that high school students who do team sports have more positive characteristics than those who do individual sports and those who do not do any sports. In their study, İslam and İmamoğlu (2019) stated that physical education teacher candidates' attitudes towards the teaching profession may increase due to the socialization, responsibility, belonging and association characteristics of sports. In this study, it was found that the social appearance anxiety of the students who were satisfied with their body weight and height were lower than the students who were not satisfied. And this difference is statistically significant $(p<0.001)$. It may be beneficial for the participants to receive psychological support about their height. It is recommended that they do sports and pay attention to their nutrition in order to keep their body weight at the desired level.

In conclusion, social appearance anxiety was found to be similar according to gender in this study. It differed according to the field of study of the students. The social appearance anxiety levels of the students receiving sports education are the lowest. Anxiety levels of students who receive art education are higher than those who receive sports education. The social appearance anxiety of the students who did not receive sports and art education is the highest. In order to reduce social appearance anxiety, students should be supported in sports and art education and practice.

\section{REFERENCES}

1. Alemdağ, S.,Öncü E.,(2015). Examination of Teacher Candidates' Participation in Physical Activity and Social Appearance Anxiety, International Journal of Science Culture and Sport (IntJSCS), Special Issue 3;287-300. Doi : 10.14486/IJSCS291

2. Ebem V. (2019). Investigation of Social Appearance Anxiety Levels of High School Students in Terms of Different Variables (Example of Bitlis and Yozgat Province), Ağrı İbrahim Çeçen University Social Sciences Institute Physical Education and Sports Department Master Thesis. http://acikerisim.agri.edu.tr/xmlui/bitstream/handle/20.500.12 501/1886/592630. pdf?sequence=1\&isAllowed=y

3. Ermiş E., İmamoğlu G. (2019). The Effects of Sport Education and Fine Arts Education on Social Appearance Anxiety, Journal of Education and Training Studies,7(6);1-6. doi:10.11114/jets.v7i6.4147.

4. Claes, L., Hart, T. A., Smits, D., Van den Eynde, F., Mueller, A., \& Mitchell, J. E. (2012). Validation of the social appearance anxiety scale in female eating disorder patients. European Eating Disorders Review, 20(5); 406-409. DOI: 10.1002/erv.1147

5. Çepikkurt, F. ,Çoşkun, F., (2010). Social Physics Anxiety and Body Image Satisfaction Levels of University Dancers. Pamukkale Journal of Sport Sciences, 1(2); 17-24. https://arastirmax.com/tr/publication/pamukkale-sporbilimleri-dergisi/

6. Çinar V. ,Bostancı Ö., İmamoğlu O., Kabadayı M. Şahan H. (2004). Anthropometric Differences in the Athlets who Are Students in Accordance with the Branch and Sexuality, Journal of Physical Education and Sport Sciences, 6(2); 2634.

https://scholar.google.com/citations?view_op=view_citation\& $\mathrm{hl}=$ tr\&user=PBCGQ60AAAAJ\&cstart $=100 \&$ pagesize $=100 \& \mathrm{ci}$ tation_for_view=PBCGQ60AAAAJ:-nhnvRiOwuoC

7. Çınar, H., Keskin, N. (2015). The effect of students' social appearance anxiety on their learning place preferences, Electronic Journal of Vocational Colleges, 14; 457-464. https://docplayer.biz.tr/8559476-Ogrencilerin-sosyalgorunus-kaygisinin-ogrenim-yeri-tercihlerine-etkisi-effect-onlearning-place-choice-of-social-appearance-anxiety-ofstudents.html

8. Dindar, M., Akbulut Y., (2015). "Role of self-efficacy and social appearance anxiety on gaming motivations of MMOFPS players", Computers and Education, Volume 81;26-34. https://doi.org/10.1016/j.compedu.2014.09.007

9. Doğan, T., (2009). Examination of cognitive and selfevaluation processes in terms of social anxiety. Unpublished Doctoral Thesis. Sakarya University Institute of Social Sciences, Sakarya https://acikerisim.sakarya.edu.tr/bitstream/handle/20.500.12 619/77624/T04306. pdf?sequence $=1$ \&isAllowed $=y$

10. Edwards, S. D.,Ngcobo, H. S., Edwards, D. J. and Palavar, K., (2005).Exploring the relationship between physical activity, psychological well-being and physical selfperception in different exercise groups. South African Journal for Research in Sport, Physical Education and Recreation, 27(1); 59-74. DOI: 10.4314/sajrs.v27i1.25908

11. Eren Gümüş, A., (2006). A Prediction of Social Anxiety Based on Self Esteem and Dysfunctional Attitudes, Türk Psikolojik Danışma ve Rehberlik Dergisi,3(26),63-75. https://dergipark.org.tr/tr/download/article-file/200163

12. Hart, T. A., Flora, D. B., Palyo, S. A., Fresco, D. M., Holle, C., \&Heimberg, R. C., (2008). Development and Examination of the Social Appearance Anxiety Scale. Assessment, 15; 48-59. Doi:10.1177/1073191107306673.

13. Heise D. (2004). Is Visual Culture Becoming Our Canon of Art? Art Education. 57 (5), 41-46 (September). ttps://www.academia.edu/3536899/Is_visual_culture_becomi ng_our_canon_of_art 
14. İmamoğlu G., Satıcı A., Ermiş E., Ermiş A. (2018). Social Appearance Anxiety in Students of the Faculties of Sport Sciences, Fine Arts and Education, $6^{\text {th }}$ International Conference on Science Culture and Sport, Proceedings Book, Ankara: 525-534, www.iscs -a.org.

15. İslam A., İmamoğlu O. (2019). The Examination of Attitudes Relating to Teaching Professions of University Students Receiving Sport Education (Sample of Ordu University), MANAS Journal of Social Studies, 8(1);1349-1361. https://dergipark.org.tr/tr/pub/mjss/issue/42874

16. Kara A. (2016). Examining the Relationships between Social Appearance Anxiety and Shyness, Journal of Individual and Society, 6(11);

95-106. https://dergipark.org.tr/tr/download/article-file/224415

17. Kılıç, M., (2015). Investigation of the Relationship between University Students' Social Appearance Anxiety and SelfEsteem and Loneliness Levels. Master Thesis, Selcuk University Health Sciences Institute, Konya. https://docplayer.biz.tr/54389551-Universite-ogrencilerininsosyal-gorunus-kaygilari-ile-benlik-saygilari-ve-yalnizlikduzeyleri-arasindaki-iliskinin-incelenmesi.htm

18. Koca F., İmamoğlu G., İmamoğlu O. (2018).Sports Status of High School Students and Investigation of Personality Characteristics by Gender, The Journal of Academic Social Science,6 (80); 31-42. DOI: 10.16992/ASOS.14267

19. Leary, M. R., \& Kowalski, R. M. (1995). Social anxiety. New York: Guilford

20. Marquez, D. X.,McAuley, E., (2001).Physique anxiety and self-efficacy influences on perceptions of physical evaluation. Social Behavior and Personality: an international journal, 29(7), 649-659. DOI: https://doi.org/10.2224/sbp.2001.29.7.649

21. Mülazimoğlu B., Erturan İlker Ö, G., Arslan, Y. (2014).Achievement Goals in Turkish High School PE Setting: The Predicting Role of Social Physique Anxiety. International Journal of Educational Research, 67;30-39. https://dergipark.org.tr/tr/download/issue-full-file/31129

22. Soylu Y.,Atik F.,Öçalan M. (2017). Investigation of Adolescents' Social Appearance Anxiety Levels, Journal of
Sport and Educational Sciences, SI (1), 38-45. https://dergipark.org.tr/tr/pub/sbsebd/issue/33388/371488

23. Tekeli Ş.C., (2017). Comparison of Social Appearance Anxiety and Academic Self-Efficacy Levels of Physical Education and Sports Teacher Candidates and Other Teacher Candidates, Bartın University Institute of Educational Sciences Physical Education and Sports Teaching Department Physical Education and Sports Teaching Master's thesis. https://acikerisim.bartin.edu.tr/handle/11772/336

24. Telli E.,Ünal Z., (2016). Social Appearance Anxiety According to Socio-Demographic Characteristics of University Students: A Field Study, Mehmet Akif University Journal of Social Sciences Institute, 8(5); 134-146. http://ijaep.com/Journal/vol.9.9.pdf

25. Yıldırım, T., Çırak, Y. ve Konan, N., (2011). Social anxiety in teacher candidates. Journal of Inönü University Faculty of Education, $12(1)$; https://dergipark.org.tr/tr/pub/inuefd/issue/8700/108649

26. Yamak B., Imamoğlu O., Çebi M. (2016). The Effects of the Physical Fitness Levels of Adolescents on Body Image, SelfConcept and Stress Levels, The Journal of Academic Social Science, 4 (34);191-201. DOI: 10.16992/ASOS.6542

27. Yamak B., İmamoğlu O., İslamoğlu İ.,Çebi M. (2018). The Effects of Exercise on Body Posture, Turkish Studies Social Sciences, 13(18); 1377-1388. DOI: http://dx.doi.org/10.7827/TurkishStudies.13911

28. Yousefi, B.,Hassani, Z., \&Shokri, O. (2009). Reliability and factor validity of the 7- item social physique anxiety scale (SPAS-7) among university students in Iran. World Journal of Sport Sciences, 2(3); 201-204.

29. Yüceant, M.,Unlü H. (2017). The analysis of social appearance anxiety levels of physical education teacher candidates in terms of different variables, Turkish Journal of Sport and Exercise, 19(1); 102-108. http://dergipark.gov.tr/tsed 